\title{
Molecular epidemiology of rotavirus A and adenovirus among children with acute diarrhea in Hangzhou, China
}

\author{
Wei Li ${ }^{1}$, Wenqing Xiang ${ }^{1}$, Cixiu Li ${ }^{2}$, Jialu Xu ${ }^{3}$, Dongming Zhou ${ }^{1}$ and Shiqiang Shang ${ }^{1 *}$
}

\begin{abstract}
Background: Rotavirus A (RVA) and adenovirus (Adv) are important causes of acute diarrhea in children. RVAs are classified into G and P genotypes based on viral proteins (VP)7 and VP4 gene and Adv contains over 70 genotypes based on hexon and fiber gene. This study aimed to characterize the molecular epidemiology of RVA and Adv in children with acute diarrhea during 2017-2018 in Hangzhou.

Methods: The stool samples were collected and tested for RVA and Adv by reverse transcription-quantitative PCR (RT-qPCR) assay. The RVA positive samples were detected by RT-PCR for VP7(G) and VP4([P]) genotypes, and the Adv positive samples were detected by PCR for genotyping by the target to hexon gene.

Results: Among 228 RVA-positive samples, G9 was detected as the most frequent genotype (195/228, 85.5\%), followed by G3 (20/228, 8.8\%), G2 (7/228, 3.1\%) and G1 (6/228, 2.6\%). G9 strains were closely related to strains from China and neighboring countries, as well as the USA. On the other hand, P[8] strains were detected in 219 (96.1\%) samples with most closely related to one strain from Malawi, and P[4] in 9 (3.9\%) samples. G9P[8] $(84.6 \%, 193 / 228)$ was the most prevalent rotavirus A strains, followed by G3P[8] (8.8\%, 20/228), G2P[4] (3.1\%, 7/228), G1P[8] (2.6\%, 6/228) and G9P[4] (0.9\%, 2/228). Of 167 Adv-positive cases, 2 different genotypes were identified with 152 (91.0\%) of Adv41 and 15 (9\%) of Adv-40. All Adv strains were closely related to prototype strains of Adv types 40 and 41 in India.
\end{abstract}

Conclusions: G9P[8] of RVA and Adv-41 were the most common genotypes that caused children's acute diarrhea in Hangzhou, 2017-2018.

Keywords: Rotavirus A, Adenovirus, Molecular epidemiology, Children

\section{Introduction}

Acute diarrhea is most commonly seen disease in young children with gastroenterological disorder and dehydration. Rotavirus A (RVA) and adenovirus (Adv) are the main viruses that cause acute diarrhea in children [1]. RVAs are non-enveloped, and double-stranded RNA viruses that belong to the Reoviridae family. According

\footnotetext{
*Correspondence: shangsq@zju.edu.cn

${ }^{1}$ Department of Clinical Laboratory, Children's Hospital, Zhejiang University School of Medicine; National Clinical Research Center For Child Health, 3333 Binsheng Road, Hangzhou 310052, People's Republic of China

Full list of author information is available at the end of the article
}

to viral proteins (VP)7 and VP4, the RVAs are classified into $G$ and $P$ genotypes [2]. Currently, there are 27 G-genotypes, 35 P-genotypes, and at least 73 G/P-genotype combinations existed. Genotypes G1-G4 and G9 are reported to be the most commonly detected G-genotypes among the children worldwide [3]. Distribution of different combinations of RVA genotypes varied both geographically and chronologically. According to a previous study, G1P[8], G2P[4], G3P [8], G4P [8] and G9P[8] are regarded as the common genotypic combinations throughout the world [4].

Adenovirus is a linear, double-stranded DNA virus with a genome size of $26-45 \mathrm{~kb}$. Over 70 genotypes in seven

c) The Author(s) 2020. This article is licensed under a Creative Commons Attribution 4.0 International License, which permits use, sharing, adaptation, distribution and reproduction in any medium or format, as long as you give appropriate credit to the original author(s) and the source, provide a link to the Creative Commons licence, and indicate if changes were made. The images or other third party material in this article are included in the article's Creative Commons licence, unless indicated otherwise in a credit line to the material. If material is not included in the article's Creative Commons licence and your intended use is not permitted by statutory regulation or exceeds the permitted use, you will need to obtain permission directly from the copyright holder. To view a copy of this licence, visit http://creativeco mmons.org/licenses/by/4.0/. The Creative Commons Public Domain Dedication waiver (http://creativecommons.org/publicdomain/ zero/1.0/) applies to the data made available in this article, unless otherwise stated in a credit line to the data. 
species (Adv A-G) have been characterized and classified phylogenetically according to the nucleic acid characteristics and homology as well as their hexon and fiber protein characteristics [5]. Among these species, Adv types, especially Adv- 40 and -41 were found to frequently cause diarrhea in children [6]. In this study, the molecular characteristics of RVA and Adv in children in Hangzhou upon the onset of viral diarrhea were evaluated.

\section{Methods \\ Study population}

In this study, stool sample was collected from each child who visited Children's Hospital of Zhejiang University School of Medicine in the inpatient wards and outpatient departments and was diagnosed as acute diarrhea with suspected virus infections. According to the manufacturer's instruction, all stool samples were performed rapid antigen testing (Abon Biopharm Company, Hangzhou, China; CFDA No.: 20153402309) within 2 h after stool sample collected. The rapid antigen testing positive samples were frozen at $-80{ }^{\circ} \mathrm{C}$ for further using. The rapid antigen testing positive stool samples were randomly selected and performed for RVA and/or Adv nucleic acid detection by reverse transcription-quantitative PCR (RTqPCR) assay (Wokang biotech, China). This study was approved by the medical ethics committee of the Children's Hospital of Zhejiang University School of Medicine (NO.2018-IEC-001).

\section{Detection of rotavirus A or/and adenovirus}

Stools samples were collected and mixed with $1 \mathrm{ml}$ normal saline. The mixtures were centrifuged at $6000 \mathrm{rpm}$ at $20{ }^{\circ} \mathrm{C}$ for $30 \mathrm{~s} .200 \mu \mathrm{l}$ supernatant was separated and DNA/RNA was extracted by NAE32 nucleic acid automatic extraction instrument (Daan gene, China). The one step RT-qPCR amplification was performed in a total volume of $25 \mu \mathrm{l}$ with the SLAN 96P real time PCR System (HONGSHI, China). The reaction mixtures consisted of $5 \mu \mathrm{l}$ sample and $20 \mu \mathrm{l}$ one step RT-qPCR reagent (wokang biotech, China), respectively. Each run under the following conditions: $20 \mathrm{~min}$ at $50{ }^{\circ} \mathrm{C} ; 5 \mathrm{~min}$ at $95^{\circ} \mathrm{C} ; 5$ cycles of $10 \mathrm{~s}$ at $95^{\circ} \mathrm{C}, 15 \mathrm{~s}$ at $55^{\circ} \mathrm{C}$ and $30 \mathrm{~s}$ at $72^{\circ} \mathrm{C}$; And then followed by 35 cycles of $10 \mathrm{~s}$ at $95{ }^{\circ} \mathrm{C}$ and $45 \mathrm{~s}$ at $60{ }^{\circ} \mathrm{C}$. FAM channel was used to detect rotavirus A and HEX channel was performed to detect adenovirus. Template of one step RT-qPCR positive sample was used for further genotyping of RVA or Adv. According to manufacturer's instructions, the sensitivity of this commercial kit was at least of $1.0 \times 10^{3} \mathrm{PFU} / \mathrm{ml}$, and this assay was negative for detection of other gut pathogens, such as norovirus, astrovirus, enterovirus, Salmonella, Escherichia coli and etc.

\section{Genotyping of rotavirus $A$ and adenovirus}

The amplification of RVA VP7 and VP4 gene was performed by using 960 PCR instrument (Heal Force, China) through one-step RT-PCR assay. One-step RT-PCR assay reagents and primers were supported by Chongqing Wokang Biotechnology Co., Ltd. The forward primer of VP7 gene: 5' GAATCAAATAARTGGATATCAATG GG $3^{\prime}$, and reverse primer of VP7 gene was $5^{\prime}$ GCTACR TTTTCCCTYGGTCC $3^{\prime}$. The forward primer of VP4 gene was 5'TTTACACCACCCAMTGATTATTGG3', and reverse primer of VP4 gene was $5^{\prime}$ CTCTAAACG TTTCGAAAAAYTTCCA3'. One step RT-PCR was conducted under the following conditions: $20 \mathrm{~min}$ at $50{ }^{\circ} \mathrm{C}$; 5 min at $95{ }^{\circ} \mathrm{C}$; 5 cycles of $10 \mathrm{~s}$ at $95{ }^{\circ} \mathrm{C}, 15 \mathrm{~s}$ at $55^{\circ} \mathrm{C}$ and $30 \mathrm{~s}$ at $72{ }^{\circ} \mathrm{C}$, followed by 35 cycles of $10 \mathrm{~s}$ at $95^{\circ} \mathrm{C}$ and $45 \mathrm{~s}$ at $60^{\circ} \mathrm{C}$. The amplification of Adv hexon gene underwent genotyping. The primers were as follows: Forward primer: $5^{\prime}$ GGTCTTACATGCACATCGCC3'; and Reverse primer: $5^{\prime}$ CAAAACCCGGTTGTCGCC $3^{\prime}$. PCR assay was conducted under the following conditions: 5 min at $95^{\circ} \mathrm{C} ; 5$ cycles of $10 \mathrm{~s}$ at $95^{\circ} \mathrm{C}, 15 \mathrm{~s}$ at $55^{\circ} \mathrm{C}$ and $30 \mathrm{~s}$ at $72{ }^{\circ} \mathrm{C}$, and followed by 35 cycles of $10 \mathrm{~s}$ at $95{ }^{\circ} \mathrm{C}$ and $45 \mathrm{~s}$ at $60{ }^{\circ} \mathrm{C}$. The amplification products were purified and sequenced in the Generay company (Shanghai, China). Sequences of RVA or Adv isolates were compared to the National Center for Biotechnology Information (NCBI) database through BLAST. Nucleotide sequences of representative strains were compared with reference strains of each virus using Mafft alignment with L-INS-I algorithm. Phylogenetic analysis was performed by maximum likelihood method that is implemented in the program PhyML 3.0 with GTR model.

\section{Statistical analysis}

The results were analyzed using SPSS software (version 20.0). $X^{2}$ test was used to analyze statistical differences. Two-tailed $P$ values of less than 0.05 were considered to be statistically significant.

\section{Results}

\section{Genotyping of rotavirus A}

In study period, 35,871 samples were performed rapid antigen testing, 6196 (17.3\%) were positive for RVA and 1112 (3.1\%) were positive for Adv. The genotyped samples were randomly selected throughout the year of 2017-2018. To ensure that these samples were representative, we collect a certain number of samples according to the positive rate of each month in 2017-2018. A total of 228 RVA-positive samples were collected for this study. To determine the subtype of each RVA, the VP4 and VP7 genes of RVAs were amplified and then sequenced. Phylogenetic trees were constructed from the nucleotide 
sequences of partial VP4 and VP7 genes. Among the 228 RVA-positive cases, only 4 different RVA G genotypes were detected. Of these, G9 $(85.5 \%, 195 / 228)$ was the most frequently detected genotype $(P<0.05)$, followed by G3 (8.8\%, 20/228), G2 (3.1\%, 7/228) and G1 (2.6\%, 6/228). As shown in Fig. 1a, G2 strains detected in this study showed close association with strains of China, and G3 strains showed close association with strains of Thailand, while G1 and G9 strains showed close association with those of Japan, India, Thailand, USA as well as China. For genotype of $\mathrm{P}$ gene, 2 different $\mathrm{P}$ gene genotypes, including 219 of $\mathrm{P}[8](96.1 \%, 219 / 228)$ and 9 of $\mathrm{P}[4]$ (3.9\%, 9/228) were detected, and RVA of P[8] was significantly higher than $\mathrm{P}[4](P<0.05)$. Phylogenetic analyses (Fig. 1b) detected $\mathrm{P}[4]$ strains that are highly identical with those of China and Indonesia. However, all P[8] strains were clustered into a lineage, and showed close relation to one of the strains of Malawi (MG181725/MWI/ BID2MT/2014). Simultaneous analysis of VP7 gene and VP4 gene revealed G9P [8] $(84.6 \%, 193 / 228)$ as the most prevalent rotavirus strains that are associated with acute diarrhea in Hangzhou children $(P<0.05)$, followed by G3P[8] (8.8\%, 20/228), G2P[4] (3.1\%, 7/228), G1P[8] $(2.6 \%, 6 / 228)$ and G9P $[4](0.9 \%, 2 / 228)$.

\section{Genotyping of adenovirus}

During the study period, $167 \mathrm{Adv}$-positive samples were also randomly collected and genotyped. Of the $167 \mathrm{Adv}-$ positive samples, 2 different genotypes were identified. Adv-41 (91.0\%, 152/167) was considered to be the most frequent genotype found in Hangzhou that was significantly higher than Adv-40 (9.0\%, 15/167, $P<0.05)$. As a

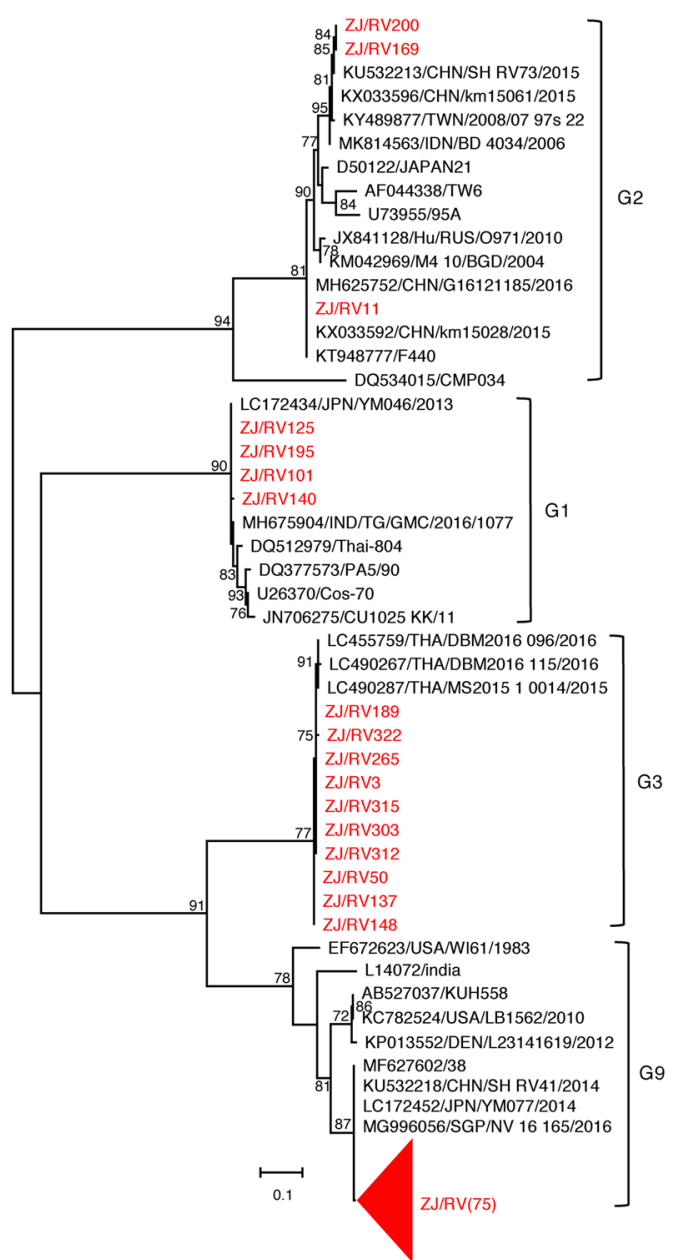

b

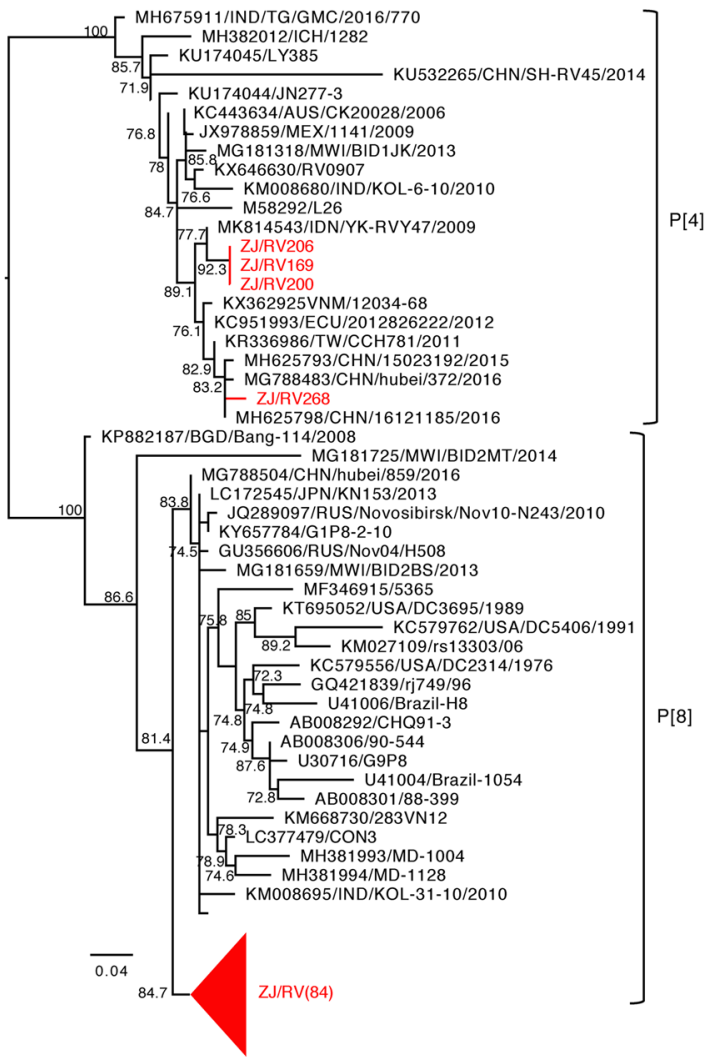

Fig. 1 Maximum-likelihood (ML) phylogenetic tree based on a portion of VP4 or VP7 gene of rotavirus A. a G gene. b P gene. Bootstrap values greater than $70 \%$ are indicated 


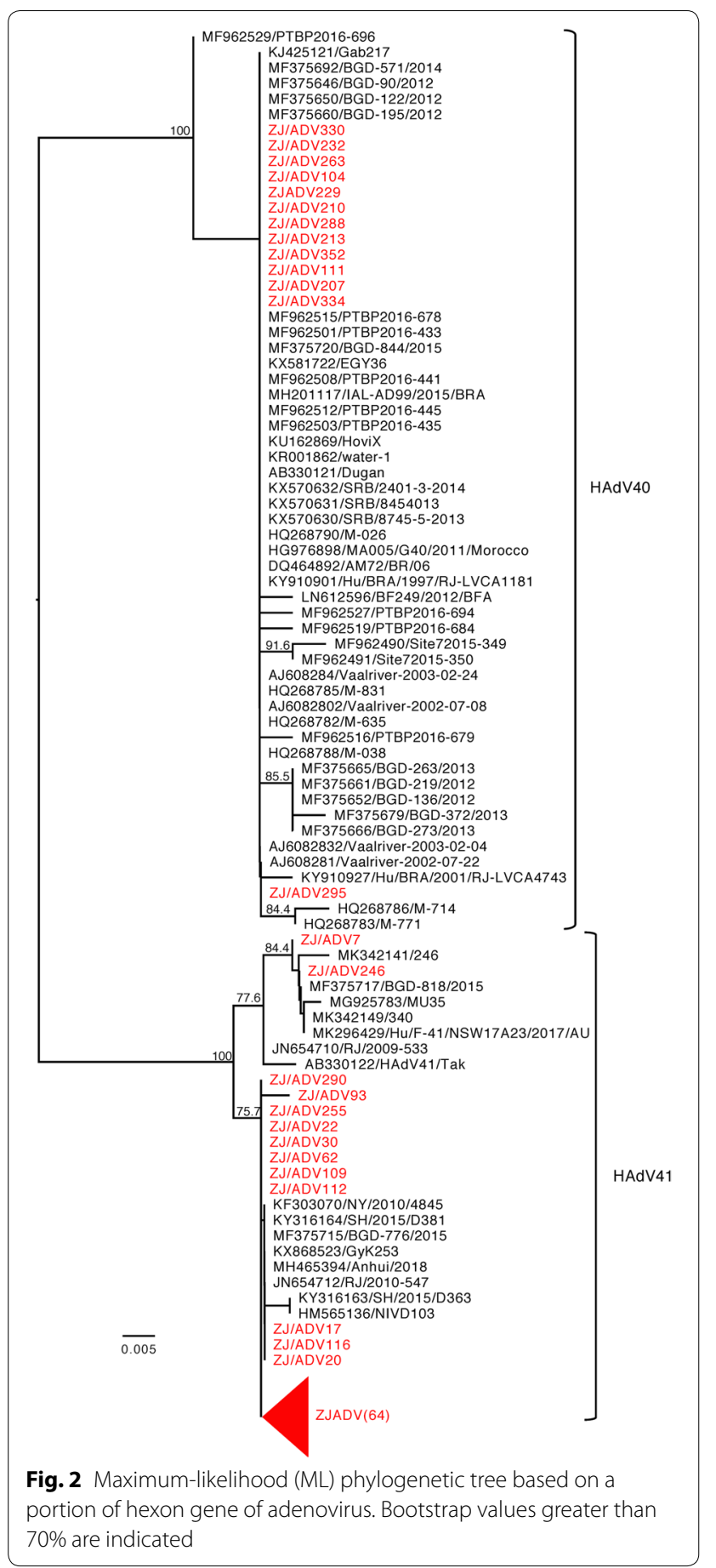

shown in Fig. 2, phylogenetic tree was constructed based on partial hexon gene when compared to the previously reported strains, including the prototype strains of Adv types 40 and 41 in India. Adv type 40 that was detected in this study exhibited a similarity of greater than $99 \%$ with the prototype strain Dugan, while Adv type 41 exhibited more than $98 \%$ similarity with the prototype strain Tak.

\section{Discussion}

Before 2010, G1 and G3 were considered as predominant rotaviruses circulating alternately around China [7-11]. After 2010, G9 began to increase and became the main epidemic subtype in the mainland of China, with a proportion of $91.8 \%$ in eastern China in 2013-2014 [12], 66.4\% in southwest China in 2014-2015 [13], and 79.4\% in Kunming in 2015-2016 [14]. Furthermore, some reports were inconsistent with these surveillance results, as G3 was the predominant subtype in Qinghai province in 2012-2015, and G1 was the major subtype in Henan province in 2009-2015 [15, 16]. However, there were fewer reports that reported about $\mathrm{G}$ surveillance results in recent years. In this study, our surveillance also suggested G9 as the most prevalent genotype in Hangzhou in 2017-2018. Also G9 strains showed close association with those of China and neighboring countries, as well as the USA. According to the previous study, P[8] and $\mathrm{P}[4]$ RVAs have been identified as the most common P-genotypes worldwide [2]. In our study, 2 different $\mathrm{P}$ gene genotypes including $\mathrm{P}[8]$ and $\mathrm{P}[4]$ were found, and $\mathrm{P}[8]$ (96.1\%) of these was the most common genotype in Hangzhou in 2017-2018. Phylogenetic tree analysis revealed that the $\mathrm{P}[8]$ strains showed close association to one of the strains from Malawi. By combining VP4 and VP7 results, G9P[8] (84.6\%) was regarded as the most common strain that caused acute gastroenteritis in Hangzhou children. The proportion of G1P [8] and G3P [8] was less than $10 \%$, and these genotypes were also common before 2010. Compared with other studies in different areas of China, our results also supported G9P [8] as the major genotype of RVA in recent years [12-14, 17]. In the future, more research should be conducted to confirm whether G9P[8] is the most popular strain in China.

In our surveillance, Adv-41 (91.0\%) was found to be the most frequent genotype infected in children in Hangzhou in 2017-2018. These results were similar to that of previous studies, wherein Adv-41 was predominant adenovirus genotype identified in Shanghai, China, 2006 [18], 92.1\% of Adv41 was detected in Brazil in 2012-2017 [19], and Adv41, 40 and Adv3 were identified as the most dominant ones in Hebei, China in 2017 [20]. Adv type 40 strains showed close association to the prototype strain Dugan, while Adv type 41 strains exhibited significant similarity with the prototype strain Tak [21]. Recently, the proportion of Adv-3 was increasing in children with diarrhea in China $[19,21]$. However, Adv-3 was not detected, which is a limitation in our study. The surveillance of Adv-3 in Hangzhou, China should be strengthened in the future.

In conclusion, G9, P[8] and G9P[8] were the most common genotypes of RVA strains, and Adv-41 was a prevalent Adv that caused acute diarrhea in children of 
Hangzhou in 2017-2018. The survey of RVA genotype and adenovirus from children with acute diarrhea warrants further research.

\section{Acknowledgements}

Not applicable.

\section{Authors' contributions}

WL and SS: designed the study and wrote the paper. WL and WX: performed the experiments. WL, JX, CL and DZ: analyzed the results and conducted the statistical analyzes. All authors read and approved the final manuscript.

\section{Funding}

This study was funded by the Medical Scientific Projects from Health Department of Zhejiang Province (2015KYA119), the National Nature Science Foundation of China (81671495 and 81701535).

\section{Availability of data and materials}

All the data are within the manuscript.

\section{Ethics approval and consent to participate}

This study was approved by the medical ethics committee of the Children's Hospital of Zhejiang University School of Medicine (NO.2018-IEC-001).

\section{Consent for publication}

Not applicable.

\section{Competing interests}

The authors declare that they have no competing interests.

\section{Author details}

1 Department of Clinical Laboratory, Children's Hospital, Zhejiang University School of Medicine; National Clinical Research Center For Child Health, 3333 Binsheng Road, Hangzhou 310052, People's Republic of China. ${ }^{2}$ Marie Bashir Institute for Infectious Diseases and Biosecurity, Charles Perkins Centre, School of Life \& Environmental Sciences and Sydney Medical School, The University of Sydney, Sydney, NSW 2006, Australia. ${ }^{3}$ Department of Neurology, Children's Hospital, Zhejiang University School of Medicine; National Clinical Research Center For Child Health, Hangzhou, People's Republic of China.

Received: 23 July 2019 Accepted: 9 April 2020

Published online: 13 April 2020

\section{References}

1. Gordon M, Akobeng A. Racecadotril for acute diarrhoea in children: systematic review and meta-analyses. Arch Dis Child. 2016;101(3):234-40.

2. Damanka SA, Agbemabiese CA, Dennis FE, Lartey BL, Adiku TK, Enweronu-Laryea CC, Armah GE. Genetic analysis of Ghanaian G1P[8] and G9P[8] rotavirus A strains reveals the impact of P[8] VP4 gene polymorphism on P-genotyping. PLoS ONE. 2019;14(6):e0218790.

3. Patton JT. Rotavirus diversity and evolution in the post-vaccine world. Discov Med. 2012;13(68):85-97.

4. Bányai K, László B, Duque J, Steele AD, Nelson EA, Gentsch JR, Parashar UD. Systematic review of regional and temporal trends in global rotavirus strain diversity in the pre rotavirus vaccine era: insights for understanding the impact of rotavirus vaccination programs. Vaccine. 2012;30(Suppl 1):A122-30

5. Lynch JP, Kajon AE. Adenovirus: epidemiology, global spread of novel serotypes, and advances in treatment and prevention. Semin Respir Crit Care Med. 2016;37(4):586.
6. Li L, Phan TG, Nguyen TA, Kim KS, Seo JK, Shimizu H, Suzuki E, Okitsu S, Ushijima H. Molecular epidemiology of adenovirus infection among pediatric population with diarrhea in Asia. Microbiol Immunol. 2005;49(2):121-8.

7. Yang XL, Matthijnssens J, Sun H, Muhamaiti J, Zhang B, Nahar S, Van Ranst M, Rahman M. Temporal changes of rotavirus strain distribution in a city in the northwest of China, 1996-2005. Int J Infect Dis. 2008;12(6):e11-7.

8. Zeng M, Zhang Y, Zhu Q, Wang X, Yu H. Clinical and molecular epidemiology of rotavirus in children with community-acquired and hospital-acquired diarrhea in Shanghai, China. Pediatr Infect Dis J. 2010;29(2):177-80.

9. Li CS, Chan PK, Tang JW. Prevalence of diarrhea viruses in hospitalized children in Hong Kong in 2008. J Med Virol. 2009;81(11):1903-11.

10. Xu J, Yang Y, Sun J, Ding Y, Su L, Fang Z, Glass RI. Molecular epidemiology of rotavirus infections among children hospitalized for acute gastroenteritis in Shanghai, China, 2001 through 2005. J Clin Virol. 2009:44(1):58-61.

11. Tong MQ, Chen LQ, Shang SQ, Zhao ZY. Analysis of VP7 serotype of rotavirus in infantile diarrhea in Hangzhou area from 2001 to 2003. Zhonghua Er Ke Za Zhi. 2005;43(8):595-8 (Article in Chinese).

12. Zhou N, Lv D, Wang S, Lin X, Bi Z, Wang H, Wang P, Zhang H, Tao Z, Hou P, et al. Continuous detection and genetic diversity of human rotavirus $A$ in sewage in eastern China, 2013-2014. Virol J. 2016;13(1):153.

13. Zhang S, Yin J, Yang J, Tian L, Li D, Zhang Q, Chen J, Xu W, Zhou X. Epidemiology and genetic diversity of group A rotavirus in acute diarrhea patients in pre-vaccination era in southwest China. J Med Virol. 2017:89(1):71-8.

14. Shen W, Sheng Y, Weng J, Wang D, Qiu D, Li C, Guan Y, Zhou X, Lin H. Molecular epidemiology of rotavirus in infectious diarrhea patients in Taizhou, 2015-2016. Dis Surveill. 2018;33(10):809-13 (article in Chinese).

15. Tian D, Liu G, Zhao S, Fan L, Lu N. Molecular epidemiological analysis of Rotavirus group A in infants in Qinghai Province from 2012 to 2015. Chin J Pest Control. 2018;4:364-6 (article in Chinese).

16. Zhao J, Shen X, Zhang B, Li X, Duan J, Wang X, Su J, Xia S. Molecular epidemiological research of rotavirus below five years old children with diarrhea in sentinel surveillance hospital of Henan Province. Chin J Virol. 2017:4:512-7.

17. Yu J, Lai S, Geng Q, Ye C, Zhang Z, Zheng Y, Wang L, Duan Z, Zhang J, Wu $S$, et al. Prevalence of rotavirus and rapid changes in circulating rotavirus strains among children with acute diarrhea in China, 2009-2015. J Infect. 2019;78(1):66-74.

18. Lu L, Zhong H, Su L, Cao L, Xu M, Dong N, Xu J. Detection and molecular characterization of human adenovirus infections among hospitalized children with acute diarrhea in Shanghai, China, 2006-2011. Can J Infect Dis Med Microbiol. 2017;2017:9304830.

19. Primo D, Pacheco GT, Timenetsky MDCST, Luchs A. Surveillance and molecular characterization of human adenovirus in patients with acute gastroenteritis in the era of rotavirus vaccine, Brazil, 2012-2017. J Clin Virol. 2018;109:35-40.

20. Qiu FZ, Shen XX, Li GX, Zhao L, Chen C, Duan SX, Guo JY, Zhao MC, Yan TF, Qi JJ, et al. Adenovirus associated with acute diarrhea: a case-control study. BMC Infect Dis. 2018;18(1):450.

21. Banerjee A, De P, Manna B, Chawla-Sarkar M. Molecular characterization of enteric adenovirus genotypes 40 and 41 identified in children with acute gastroenteritis in Kolkata, India during 2013-2014. J Med Virol. 2017;89(4):606-14.

\section{Publisher's Note}

Springer Nature remains neutral with regard to jurisdictional claims in published maps and institutional affiliations. 